\title{
Expectativas desencaixadas: o problema da construção da autolegitimidade entre policiais militares*
}

Recebido: 15.04 .20 Aprovado: 27.05 .20

\author{
Bruna Gisi** \\ \& Giane Silvestre***
}

Resumo: $O$ artigo trata da construção da autolegitimidade de policiais a partir de pesquisa qualitativa realizada com praças da Polícia Militar de São Paulo (PMESP). O objetivo é analisar o impacto das percepções e expectativas dos policiais sobre as atividades de policiamento na construção da legitimidade reivindicada por eles. Parte-se da concepção de legitimidade policial como processo dialógico continuamente atualizado nos contatos com a população. Foram realizadas 28 entrevistas em profundidade com praças da PMESP em oito distritos da cidade de São Paulo. As análises indicam uma disjunção entre a visão dos policiais sobre sua função e autoridade e a percepção sobre as respostas da população. Os entrevistados demonstram confiança em sua autoridade e valorização do trabalho de controle do crime, mas percebem um déficit de legitimidade nas respostas da população, que questiona sua autoridade nas abordagens. Consideram ainda certas demandas da população como excessivas e desvios de sua função.

Palavras-chave: Legitimidade. Autolegitimidade. Polícia Militar. Contato. Abordagem policial.

\section{Disconnected expectations: the problem of self-legitimacy construction among military police officers}

Abstract: The article aims at analyzing the construction of police self-legitimacy from a qualitative research conducted with officers from the Military Police of São Paulo. The objective is to analyze the impact of the officer's perceptions and expectations toward policing in the legitimacy claimed by them. The work departs from a conception of legitimacy as a dialogic process continually enacted during the contacts with the population. The research consisted of 28 in depth interviews with police officers from 8 districts of São Paulo. The analysis shows a disjunction between the view the officers share about their function and authority and the perception of the population responses to their work. The interviewees show confidence in their authority and appreciation for the work of fighting crime, but perceive a legitimacy deficit in the responses of citizens who often question their authority during stops. They also consider the populations demands excessive and misleading.

Keywords: Legitimacy. Self-legitimacy. Military Police. Contact. Stop and frisk.

\author{
* Este artigo foi \\ desenvolvido com o \\ apoio da Fundação \\ de Amparo à \\ Pesquisa do Estado \\ de São Paulo \\ (Fapesp). Utiliza \\ dados coletados \\ nas pesquisas de \\ pós-doutorado das \\ autoras. Processos \\ N. 2017/04103-0 e \\ N. 2017/04428-6 da \\ Fapesp. As pesquisas \\ desenvolvidas \\ integram o Programa \\ Cedip-Fapesp \\ "Construindo a \\ democracia no \\ cotidiano: direitos \\ humanos, violência \\ e confiança \\ institucional" \\ desenvolvido pelo \\ Núcleo de Estudos \\ da Violência (NEV- \\ USP), processo $\mathrm{N}$. \\ 2013/07923-7 da \\ Fapesp. \\ ** Bruna Gisi \\ é doutora pelo \\ Programa de \\ Pós-Graduação \\ em Sociologia da \\ Universidade de \\ São Paulo (2016). \\ Realizou pós- \\ doutorado no Núcleo \\ de Estudos da \\ Violência (2017- \\ 2018). É professora \\ do Departamento \\ de Sociologia da \\ Universidade de
}


São Paulo (USP) e pesquisadora do Núcleo de Estudos da Violência da (NEVUSP), São Paulo, SP, Brasil.

Orcid: 0000-0003-

1150-5808.

<brunagisi@usp.br>.

*** Giane Silvestre é doutora (2016)

em sociologia pela Universidade Federal de São Carlos (UFSCar), pesquisadora de pós-doutorado no Núcleo de Estudos da Violência da Universidade de São Paulo (NEV-USP), São Paulo, SP, Brasil. Orcid: 0000-00028639-8843. <silvestregiane@ usp.br>.

\section{Apresentação}

$\mu$ s organizações policiais e suas práticas são objeto de estudos já consolidados nas ciências sociais, tanto na esfera nacional como na internacional. Um dos principais autores que discute o policiamento e sua função é Egon Bittner (2003), que, em seus trabalhos, explora a constatação empírica de tensão entre os aspectos oficiais da polícia e as atividades cotidianas desempenhadas pelos policiais. O autor argumenta que a definição oficial do papel da polícia - aplicar a lei e combater o crime - não traduz a maior parte do trabalho que os policiais realizam. Com a proposta de considerar as expectativas que a população efetivamente expressa quando aciona a polícia com a persuasão de que exerça o papel de polícia na prática, o autor defende que esse papel envolve

[...] enfrentar todos os tipos de problemas humanos quando (e na medida em que) suas soluções tenham a possibilidade de exigir (ou fazer) uso da força no momento em que estejam ocorrendo (Bittner, 2003: 136).

De acordo com o autor, a manutenção de um modelo oficial de atividade policial baseado na organização militar e discrepante com o seu funcionamento efetivo teria consequências negativas como inadequação do treinamento, aumento do cinismo e incentivo à regra do silêncio entre os policiais, deslocamento da má conduta para áreas não regulamentadas, entre outras.

No caso brasileiro, esse achado é muitas vezes visto como parte dos mecanismos que reproduzem a atuação policial contraditória com o Estado democrático de direito. O uso excessivo de força letal (Pinheiro, 1991; Bueno, 2014, Misse et alii, 2015), a prática de tortura contra suspeitos como meio corrente de investigação criminal (Kant de Lima, 1995; 2011; Vargas, 2012) e outras violações de direitos individuais têm sido apontadas, desde o final da década de 1980, como evidências de que um controle autoritário da ordem pública continua a orientar as instituições policiais brasileiras mesmo com o fim da ditadura militar (Pinheiro, 1991). A persistência de um modo de funcionamento informal com códigos de conduta e estoque de conhecimento não vinculados às diretrizes legais abriria margem para abusos e violações.

Quais os efeitos dessa discrepância entre o modelo oficial da atividade policial e seu funcionamento prático para a legitimidade da polícia? Recentemente, uma literatura internacional tem se dedicado a investigar empiricamente a legitimidade das organizações policiais a partir da proposta de Tom Tyler (1990). O autor defende a 
importância da qualidade dos contatos cotidianos entre a população e os representantes das organizações policiais para a percepção de legitimidade, desenvolvendo, assim, uma noção processual de legitimidade. Essa dimensão processual é ainda mais marcante no trabalho de Anthony Bottoms e Justice Tankebe (2012), no qual os autores destacam a necessidade de considerar o aspecto dialógico da legitimidade. De acordo com os autores, é preciso pensar a legitimidade como uma discussão contínua em que a reivindicação de autoridade por parte dos detentores do poder é um lado importante da relação.

De modo a contribuir com esse campo de pesquisa, o objetivo deste trabalho é analisar um aspecto ainda pouco explorado pela literatura nacional: como e se a tensão entre o modelo oficial da instituição, seu funcionamento prático, e a expectativa dos policiais influencia a autolegitimidade desses agentes. Para tanto, parte-se de uma pesquisa qualitativa desenvolvida com policiais militares, que trabalham em companhias localizadas em diferentes regiões da cidade de São Paulo, e busca-se explorar as percepções e expectativas dos policiais sobre as atividades de policiamento para relacioná-las com a legitimidade reivindicada por esses atores.

O artigo está divido em cinco partes, além desta apresentação. A primeira parte apresenta o debate da literatura nacional sobre as organizações policiais brasileiras, com ênfase nas análises sobre as tensões existentes entre o modelo oficial das polícias e seu funcionamento prático. A segunda é dedicada à perspectiva sobre a legitimidade adotada no presente trabalho, em especial o conceito de autolegitimidade, bem como à agenda de pesquisa que vem sendo desenvolvida a partir dessa abordagem. A terceira parte detalha a pesquisa empírica e os dados analisados no artigo. A quarta e a quinta parte apresentam os resultados da pesquisa relativos à autolegitimidade dos policiais e suas percepções sobre as demandas e as reações da população. Ao final, o item "Considerações finais" sintetiza o argumento formulado a partir da interpretação dos achados. O que as análises demonstram é que existe uma disjunção entre a visão dos policiais sobre sua função e autoridade e as percepções sobre as respostas e demandas da população ao que eles reivindicam nos contatos diários.

\section{O oficial e a prática nas polícias brasileiras}

A Constituição brasileira divide os serviços policiais estaduais em duas organizações diferentes: a Polícia Militar - responsável pelo patrulhamento ostensivo da ordem pública - e a Polícia Civil - responsável pela investigação criminal. Ainda que essas duas organizações sejam independentes e apresentem estruturas próprias, os estudos sobre o modo de funcionamento rotineiro das duas polícias demonstram 
que elas coincidem em um aspecto: as duas organizações exibem tensões entre a estrutura, o conhecimento e o treinamento formal e o estoque de conhecimento e código de conduta práticos e informais.

Nesse sentido, as pesquisas sobre a Polícia Civil com frequência se concentram na forma como os policiais e os delegados desenvolvem atalhos e códigos informais de conduta para realizar as atividades investigativas e atingir as demandas de eficiência. As análises pioneiras desenvolvidas por Antônio Luiz Paixão (1982; 1988) sobre a Polícia Civil contribuíram significativamente para a construção desse diagnóstico. Paixão (1982) mostra de que maneira a "lógica em uso" adotada pelos policiais para o desempenho prático de suas atividades é determinada menos pelos formalismos legais e mais por ideologias e tipificações que tornam mais econômica a atividade policial. A polícia seria uma organização que sofreria de modo particularmente intenso com o "paradoxo da discrição": quando se observa as circunstâncias práticas do trabalho policial, nota-se que há coexistência e tensão entre controles burocráticos formais rígidos e autonomia de policiais de nível hierárquico inferior. Em sua pesquisa empírica nas delegacias, Paixão identifica que, no exercício dessa autonomia, os policiais empregam seu estoque de conhecimento de senso comum, o que, com frequência, envolve "lei" e "ordem" como ideais conflitantes de conduta (Paixão, 1988).

As análises de Roberto Kant de Lima (2011) também enfatizam que o caráter inquisitorial das práticas policiais brasileiras poderia explicar o uso frequente de coerção e tortura para obter confissões dos acusados. Os policiais justificam seu comportamento ilegal alegando ter um julgamento mais preciso dos fatos devido a sua "experiência" e conhecimento da "verdade dos fatos" melhor do que as autoridades judiciais. Kant de Lima mostra que as ações da polícia são majoritariamente orientadas por uma "ética implícita", um "código de honra" a que todos os policiais precisam aderir para lidar com "criminosos". Faz parte desse conhecimento informal uma diferenciação cultural entre grupos populacionais que justificaria, por exemplo, a necessidade de aplicar violência quando se lida com grupos de status social baixo. O autor argumenta que essa ética, transmitida e reproduzida de forma tradicional, permite aos policiais aplicarem alternadamente leis gerais e normas particulares, a depender da pessoa interpelada.

A existência de tensões entre os procedimentos e regulamentos formais e as formas de conduta práticas e informais, identificadas nos estudos sobre a Polícia Civil, é também um aspecto destacado pela literatura sobre a Polícia Militar. Nesses estudos, no entanto, o foco é usualmente a discrepância entre o caráter militar da estrutura organizacional e as habilidades altamente discricionárias exigidas pelas atividades de patrulhamento. 
Nessa direção, Jacqueline Muniz (1999) mostra como a discricionariedade intrínseca às atividades policiais de lidar com todos os tipos de eventos e emergências não traduz a racionalidade legal e constitui uma "zona cinzenta" do trabalho da polícia - constituída tanto por ações adequadas como por ações violentas e arbitrárias - que não é visível para a corporação e para a população. Muniz demonstra que os policiais aprendem on the job que usualmente não é possível conciliar a lei, os procedimentos necessários para usar a força, a validação moral da ação e a produção de resultados efetivos e satisfatórios. Essa percepção, por sua vez, encoraja os policiais a abandonarem o que foi aprendido nos manuais durante o treinamento na academia, já que não os ajudaria a lidar com as situações de intervenção. Consequentemente, eles cultivam uma crença que o policiamento é algo que se aprende "nas ruas", valorizando as experiências pessoais e o conhecimento prático aprendido com os policiais mais experientes. Não por acaso, uma das características mais valorizadas pelos policiais - o chamado "tirocínio policial" - é uma qualidade construída mediante o "tempo de rua" que um policial dispõe. É a capacidade que o policial adquire nas ruas para identificar um suspeito ao primeiro olhar e os signos da suspeição (Sinhoretto et alii, 2014: 133).

No que diz respeito ao controle disciplinar feito pela organização da Polícia Militar, Muniz (1999) o considera inadequado para punir ou recompensar os policiais por sua performance profissional. O medo de ser punido favorece o encobrimento dos processos de tomada de decisão, amplia a insegurança na escolha de um curso de ação e aumenta a probabilidade de práticas arbitrárias na interação com os cidadãos.

A análise de Haydée Caruso e copartícipes (2010), sobre a dinâmica da produção, transmissão e aprendizagem do conhecimento na Polícia Militar, aponta como a formação continuada na organização é fragmentada e pouco divulgada; os policiais e os oficiais desenvolvem suas próprias técnicas para aprender como proceder nas ruas. Se eles aprendem na prática, uma estratégia adotada é reproduzir o que os policiais mais experientes fazem. Essa estratégia é também adotada pelos oficiais de médio escalão, já que eles também sentem que saem da academia para enfrentar o novo nem sempre preparados para diversas atividades enfrentadas no trabalho cotidiano. Como suas atribuições incluem comandar e administrar outros policiais, a baixa capacidade de comando pode minar a autoridade desses oficiais sobre os policiais.

Como mencionado, um dos principais problemas identificados no treinamento dos policiais é sua incongruência com as atividades cotidianas de patrulhamento. Enquanto os policiais precisam principalmente usar sua discricionariedade para nego- 
ciar as situações, mediar conflitos e lidar com eventos não criminais (Muniz \& Silva, 2010), o treinamento é baseado na ideologia repressiva e punitiva para condicionar os policiais a obedecer ordens, desconsiderando a autonomia necessária para o trabalho (Teixeira, 2009; Kant de Lima, 2011). Nessa direção, Paula Poncioni (2005; 2007) mostra que o modelo profissional transmitido nas academias de polícia não prepara os policiais para interagir com a população ou para mediar conflitos, está prioritariamente focado nos aspectos legais do trabalho e em "combater o crime". Essas inadequações ficam evidentes também na análise da legislação disciplinar da organização da Polícia Militar, dedicada quase exclusivamente ao comportamento interno à organização e à manutenção da hierarquia e da disciplina, estabelecendo uma forma de controle autoritária baseada na repressão que permite punições injustas sem o direito de defesa (Cano \& Duarte, 2012; Muniz, 2008).

Um último aspecto da estrutura formal das organizações policiais brasileiras que parece estar associada com as tensões formal/informal é sua hierarquia excludente. Apesar das várias diferenças entre as polícias civil e militar, esse é um traço comum entre elas. Kant de Lima (2011) destaca as consequências de haver carreiras separadas para os que comandam (oficiais e delegados) e os policiais que atuam na rua (agentes e policiais/praças). A grande diferença salarial, a separação completa da instrução profissional e a impossibilidade de policiais de nível inferior acenderem às posições de comando produz uma estrutura organizacional elitista e excludente que promove o sentimento de oposição e disputa entre os dois grupos.

\section{A autolegitimidade de policiais}

Recentemente um grupo de pesquisadores tem se dedicado a analisar as organizações policiais a partir de pesquisas empíricas sobre legitimidade influenciados pelos trabalhos de Tom Tyler (1990; 2003). Esses pesquisadores partem da discussão sobre a efetividade do modelo normativo de controle social em contraste com o modelo instrumental defendido pelas teorias da dissuasão. Tyler (1990) argumenta que a obediência à lei pode ser influenciada pelo compromisso normativo das pessoas com a obediência e não apenas pelo medo da punição. Se obedecer à lei é visto como apropriado porque é assim que as pessoas devem comportar-se, a obediência seria voluntária, independente do risco da punição. De acordo com Tyler, uma forma de atingir esse comprometimento normativo é pela legitimidade, ou seja, o sentimento de que a autoridade que aplica a lei "tem o direito de ditar comportamento" ("has the right to dictate behavior") (Tyler, 1990: 4). Ao identificar empiricamente a associação positiva entre obediência voluntária e legitimidade policial, o autor também busca investigar os fatores que podem influenciar os julgamentos públicos sobre a legitimidade da polícia. Para tanto, desenvolveu o que 
ficou conhecido como o modelo da justiça processual (procedural justice model) de acordo com o qual, a legitimidade é obtida como resultado das interações entre os cidadãos e os servidores públicos, avaliada pelo tratamento justo, igualitário e transparente, baseado em uma comunicação acessível e respeitosa, despendida pelos agentes do Estado.

Em uma revisão crítica do modelo de Tom Tyler, Anthony Bottoms e Justice Tankebe (2012) recuperam a discussão conceitual sobre legitimidade e destacam que um aspecto importante da definição weberiana diz respeito à reivindicação contínua e ao cultivo da legitimidade por parte dos detentores de poder. Embasados nesse ideário, sugerem que é preciso considerar o caráter dialógico e relacional da legitimidade que opera como "discussão perpétua" entre a reivindicação dos detentores de poder e as respostas da audiência. A legitimidade dos detentores de poder seria uma precondição para que o público reconheça a legitimidade da instituição. O cultivo da crença no direito moral dos próprios detentores de poder é necessário antes que eles possam reivindicar a obrigação moral de obediência à população (Bottoms \& Tankebe, 2012: 129). Essa crença - denominada autolegitimidade pode ser definida como o nível de confiança que um funcionário público dispõe sobre sua própria legitimidade, considerando-se apto para assumir sua autoridade (Tankebe, 2010; 2011).

Ao incorporar na noção de legitimidade a perspectiva daqueles que exercem o poder, essa perspectiva torna possível ter em conta situações de "disjunção" na relação de autoridade. Ao considerar a distinção proposta por Joseph Raz (2009) entre (i) poder bruto (naked power); (ii) autoridade de facto; e (iii) autoridade legítima, Bottoms e Tankebe desenvolvem a dinâmica entre reivindicação e reconhecimento que constitui a legitimidade. Na relação de "poder bruto", os que estão no comando não reivindicariam nenhum direito ao poder e não esperam dos subordinados nenhuma obrigação ou dever de obediência. A coerção física, o medo ou um cálculo das consequências garantiriam o acatamento das normas. No caso da autoridade de facto, também há o exercício efetivo de poder sobre pessoas, mas pautado na reivindicação de legitimidade, de direito ao poder, por parte dos que comandam. É isso que permitiria chamar essa relação de autoridade. Por fim, a autoridade legítima seria aquela que não só reivindica o direito de mandar e a obrigação de obediência, mas que tem essa reivindicação reconhecida pelos que estão submetidos ao seu poder.

A partir dessa proposta, torna-se possível considerar situações em que aqueles que exercem poder reivindicam ter direito de governar sem, no entanto, receber o reconhecimento desse direito por parte de seu grupo. Para a compreensão da 
dinâmica da legitimidade, portanto, torna-se necessário investigar a existência e o conteúdo dessa reivindicação por parte dos que exercem poder.

Considerar a perspectiva dos servidores públicos sobre sua legitimidade ajuda a identificar as justificativas para suas práticas, bem como suas crenças no direito moral de exercer a autoridade. Isso é particularmente importante para os servidores que estão em contato direto com o público, como os policiais, sobretudo aqueles que ocupam os níveis inferiores da hierarquia institucional - no caso da Polícia Militar brasileira, os praças, grupo formado por soldados, cabos e sargentos. Este grupo, ao mesmo tempo em que está na posição menos prestigiada da hierarquia profissional, apresenta um elevado grau de discricionariedade e de poder na relação cotidiana com o público. É o que Michael Lipsky (2010) caracteriza como "burocratas de nível de rua", pois são os funcionários responsáveis pelo primeiro contato com o público e representam diretamente o Estado perante os cidadãos. Assim, embora possam ter menos poder dentro da hierarquia de suas próprias instituições, suas ações - positivas ou negativas - podem ter impacto na legitimidade de toda instituição. Além disso, como destacam Bottoms e Tankebe (2012), por estarem em contato direto com o público, os policiais têm maior probabilidade de vivenciar situações em que sua autoridade é contestada pela população. É esperado que a necessidade de confiança e o cultivo de sua legitimidade seja algo especialmente significativo para esses agentes. Por sua vez, a possível percepção dos policiais de que a população não reconhece sua autoridade poderia estar relacionada com o apoio ao uso da força (Tankebe, 2010).

A discussão da autolegitimidade foi incorporada por diversas pesquisas que têm investigado empiricamente as instituições policiais, destacando sua importância para o exercício das funções e relacionando-a com fatores relativos à existência de procedimentos justos no exercício da autoridade interna à instituição (Tankebe, 2010; Bradford \& Quinton, 2014; Jonathan-Zamir \& Harpaz, 2014; Myhill \& Bradford, 2013). A pesquisa conduzida por Ben Bradford e Paul Quinton (2014) concluiu que a autolegitimidade dos policiais está fortemente relacionada, entre outros fatores, à gestão democrática da polícia. A posição ocupada pelos policiais na instituição, assim como sua relação com os superiores podem influenciar de forma positiva ou negativa a maneira como exercem o policiamento nas ruas e o tratamento dado à população com a qual interagem. Os autores destacam que a relação com a população também pode ter papel importante para a autolegitimidade dos policiais. Se os policiais sentem que têm o apoio da população expressam maior confiança em sua autoridade. Em contrapartida, a percepção de falta de cooperação e reconhecimento por parte da população pode fazer com que os policiais adotem estilos mais combativos, o que, por sua vez, gera mais resistência dos cidadãos, em um círculo vicioso. 
A pesquisa de Andy Myhill e Ben Bradford (2013) também mostrou que um senso de valor e integração entre policiais promove o orgulho e a identificação com a instituição, reforça a legitimidade de estruturas e processos internos, bem como estimula orientações positivas para o policiamento. Os policiais que se sentiam tratados de forma justa pela instituição eram mais propensos a se identificar com ela e a ter confiança em exercer sua própria autoridade junto à população. Da mesma forma, políticas e práticas advindas de seus superiores, consideradas injustas pelos policiais, podem promover identidades e "subculturas" opostas, contrárias ao policiamento democrático. Assim, a forma como os policiais são tratados pelos superiores afeta - negativa ou positivamente - o seu comportamento nas ruas. Essa literatura demonstra, assim, que a conviç̧ão dos policiais no direito de exercer autoridade é fortemente influenciada pela justiça interna às organizações policiais e tem um efeito significativo sobre a visão de policiamento desses agentes, bem como em relação à sua atitude e conduta profissional quando em contato com a população.

No caso da pesquisa de Tal Jonathan-Zamir e Amikam Harpaz (2014), a autolegitmidade é investigada a partir da compreensão que os policiais têm de sua "legitimidade externa". Os autores buscam compreender quais são os fatores que, segundo os policiais, fazem com que os cidadãos legitimem sua autoridade. Eles defendem que, do ponto de vista da abordagem dialógica da legitimidade, essas percepções são importantes porque um diálogo envolve avaliar corretamente a expectativa da outra parte. É esperado que a compreensão dos que exercem poder sobre as fontes de sua legitimidade externa influencie seu senso de direito moral de exercer poder. Os resultados da pesquisa conduzida com policiais israelenses mostram que, distintamente das prioridades dos cidadãos - constatadas em surveys com a população -, os policiais associam sua legitimidade externa mais ao sucesso no combate ao crime do que propriamente à justiça dos processos policiais.

Cabe destacar que essas pesquisas sobre a autolegitimidade de policiais têm adotado majoritariamente a abordagem quantitativa e tratam do tema a partir da aplicação de surveys. A questão da autolegitimidade é usualmente operacionalizada a partir das seguintes questões: se o policial se sente confiante no uso da autoridade que Ihe foi conferida; se crê que ocupa uma posição de importância especial na sociedade; se acredita ser correto o policial dispor de um tipo especial de autoridade diante dos cidadãos; se o policial presume representar o interesse das pessoas que respeitam as leis; se julga que as pessoas devem sempre fazer o que pedem, contanto que as ordem sejam legais; se sente orgulho de trabalhar na polícia; se acredita que a polícia toma as decisões corretas para a população. 
O objetivo do presente trabalho é contribuir com o estudo da autolegitimidade a partir de uma abordagem qualitativa que permita explorar não só a existência da crença no direito moral ao exercício de poder, mas também o conteúdo que os policiais atribuem à sua autoridade e as percepções que possuem acerca das respostas da população ao exercício dessa autoridade. O estudo de Jonathan-Zamir e Harpaz (2014) também caminha nessa direção ao propor a relevância de investigar de que maneira os policiais interpretam a expectativa da população para a compreensão da dinâmica relacional da legitimidade policial. Para o entendimento dialógico da legitimidade, é importante compreender de que maneira os representantes das instituições percebem as expectativas dos cidadãos e como essa percepção se relaciona com a construção de sua autoridade. Assim, a proposta deste trabalho é justamente investigar - qualitativamente - de que maneira os policiais definem seu trabalho e como avaliam as demandas da população. A análise da autolegitimidade dos policiais considera ainda a dinâmica ressaltada pela literatura nacional de tensões entre o modelo oficial e a prática da atividade policial.

\section{Método}

Conforme indicado, portanto, a pesquisa empírica adotou uma abordagem qualitativa a fim de explorar as percepções dos policiais sobre sua própria autoridade, legitimidade e sobre as tensões entre aspectos esperados e realizados de seu trabalho. Para viabilizar a coleta de dados, foi preciso obter autorização do Comando Geral da PMESP, em um processo que demandou tempo e tramitação de ofícios em diversas instâncias da instituição. Após a concessão da autorização por parte do comando e o agendamento das visitas às companhias da PMESP, um roteiro de entrevista foi elaborado com perguntas divididas em seis blocos, a saber: (i)trajetória, (ii) formação, (iii) cotidiano de trabalho, (iv) relações internas à instituição, (v) relação e contato com a população e, por fim, (vi) identidade profissional. A maioria das entrevistas foi gravada e transcrita. Nas entrevistas em que não houve autorização para gravar, foram feitas anotações buscando registrar ao máximo as falas dos policiais. Essas anotações foram analisadas em conjunto com as transcrições.

Ao todo, foram entrevistados 28 policiais: 24 soldados, 3 cabos e 1 sargento. Todos trabalhavam com o patrulhamento ostensivo. Em relação ao gênero, a maioria é formada por homens, 25 dos 28 entrevistados. Os entrevistados também eram, predominantemente jovens, 17 deles tinham menos de 30 anos. A metade dos entrevistados havia concluído o ensino médio, requisito mínimo para ingresso na carreira, cinco possuíam ensino superior completo, seis deles superior incompleto e quatro cursaram o ensino técnico. Em relação à cor/raça dos entrevistados, dez deles se declararam negros ou pardos, 17 brancos e um não respondeu. 
O material que resultou das transcrições das entrevistas foi volumoso e, para a análise, utilizou-se o software MaxQDA ${ }^{1}$. A partir da leitura preliminar do material, foi criado um conjunto de categorias que corresponde a cada um dos blocos de perguntas do roteiro de entrevistas.

As entrevistas foram realizadas com policiais que trabalhavam em companhias localizadas em oito bairros da cidade de São Paulo. O critério de seleção dos bairros se baseou em um estudo realizado pelo Núcleo de Estudos da Violência da Universidade de São Paulo (NEV-USP), no âmbito do Programa do Centro de Pesquisa, Inovação e Difusão (Cepid) para identificação dos diferentes padrões urbanos que caracterizam a cidade de são Paulo. O objetivo desse estudo urbano-demográfico foi garantir que as pesquisas do programa contemplassem a diversidade e heterogeneidade da capital paulista que podem ter efeitos no tipo de acesso a serviços públicos e de contato que população tem com os agentes públicos (Adorno \& Nery, 2019: 187).

Assim, as áreas-chave permitem captar diferentes tipos de contatos entre cidadãos e funcionários públicos e, possivelmente, diferentes graus de satisfação e confiança nos serviços e na instituição. Tais áreas abrangem os seguintes bairros: Cidade Ademar, Jardim Paulista, Jardim Ângela, Grajaú, Iguatemi, Pirituba, Vila Matilde e Vila Andrade, como pode ser visto na Figura 1. Tendo em vista a importância da consideração dessa diversidade urbana, a pesquisa qualitativa desenvolvida com
FIGURA 1

\section{MAPA DAS ÁREAS-CHAVE DA PESQUISA CEPID}

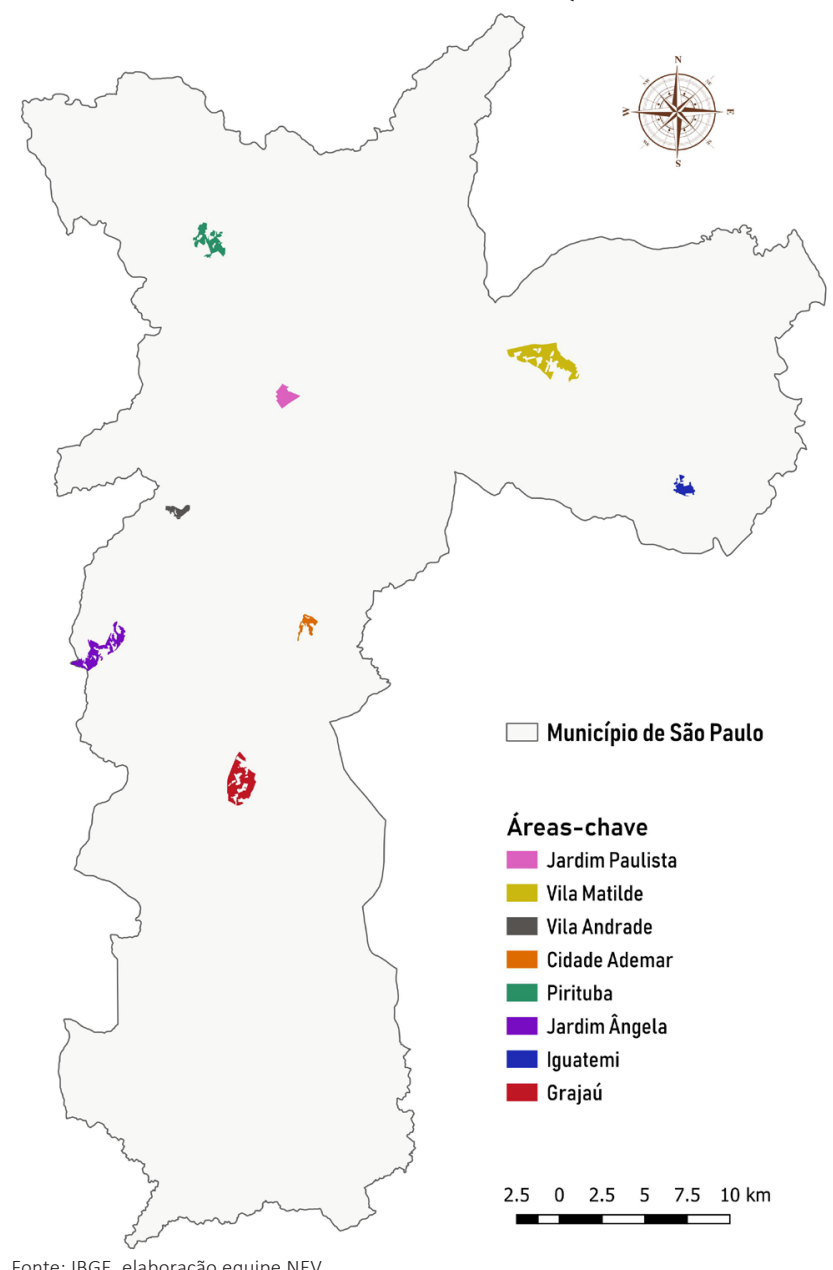

Fonte: IBGE, elaboração equipe NEV.
1. Software para análise qualitativa de textos, imagens e vídeos. 
os policiais militares seguiu a metodologia das áreas-chave e as entrevistas foram realizadas com policiais que trabalhavam em companhias localizadas precisamente nessas oito áreas-chave.

\section{Autolegitimidade}

Como forma de saber se os policiais acreditam deter o direito moral de exercer autoridade sobre a população, uma das questões do roteiro das entrevistas perguntava diretamente se os entrevistados sentiam possuir autoridade para exercer o seu trabalho e se se sentiam confiantes para exercê-la. Quase todos os policiais responderam positivamente à questão e, na grande maioria dos casos, vinculavam o fundamento dessa autoridade à lei. Nas falas, havia a ideia de ser "autorizado" pela lei a realizar o trabalho e mesmo a reagir com coerção quando as pessoas os desobedecessem.

\footnotetext{
A partir do momento que foge à normalidade nós temos, sim, que tomar providência como autoridade policial. Já houve caso que, numa desinteligência, o marido agrediu a mulher na frente da equipe. E nós tomamos providência. Contemos a pessoa, prendemos a pessoa, ele cometeu um crime, inclusive ele lesionou a mulher dele, esfaqueou a filha no dia, inclusive [...].

E nós tomamos providência como autoridade policial. Fizemos aquilo que estava previsto na Lei. Temos autoridade como policial, sim (Policial 26).

Pergunta: E você sente que tem a autoridade necessária para fazer o seu trabalho?

Resposta: Autoridade eu tenho. Sim.

Pergunta: Você sente essa confiança?

Resposta: Sim. O Estado me designou para isso. Eu sei o que quero, eu estou representando o Estado. Naquele momento eu faço cumprir a Lei. E eu sinto que sou preparado e tenho esse poder sim. Dentro da legalidade, lógico (Policial 27).
}

Outra questão explorada nas entrevistas e que indica a autolegitimidade dos policiais diz respeito à visão que expressam de sua profissão. Conforme indicado, uma das questões utilizadas na literatura para acessar a crença no direito moral à autoridade é a crença de que eles ocupam uma posição especial na sociedade, que justifica essa autoridade especial e sentem orgulho de serem policiais.

Para identificar esse aspecto, parte das questões buscava verificar o grau de identificação dos entrevistados com a instituição Polícia Militar e com a profissão de policial. Quando questionados sobre a razão para escolher a carreira policial, duas 
razões apareceram na resposta de parte dos entrevistados: a existência de familiares que trabalhavam como policiais ou no exército e o "sonho" de ser policial militar cultivado desde a infância. Como é possível observar nos relatos a seguir, muitos policiais relataram que quando eram crianças gostavam da polícia, "de viatura", "de farda", das brincadeiras de "polícia e ladrão", que viam os policiais como "super-heróis". Estes entrevistados relataram admirar a profissão como uma atividade importante para a sociedade, ofício que permite ajudar as pessoas e que gera orgulho na família.

Eu sempre vi a Polícia como super-heróis, entendeu? [...] eu tinha essa visão. Heroísmo, bravura. Eu tinha oito anos de idade quando decidi que era isso que eu queria pra minha vida (Policial 3).

Sempre admirei a profissão, tenho amigos policiais, né. E por gostar mesmo, sempre admirei de olhar quando criança. Aí depois a gente vai ficando mais velho, vai entendendo o que era um polícia, o que fazia. Né? Defender a sociedade e eu sempre me interessei por essa parte (Policial 6).

Sonho de criança. Viatura passando na rua e eu falava: um dia vou ser. Tive sempre a intenção de fazer a diferença, tentar fazer a diferença. E até hoje eu estou tentando aplicar isso (Policial 15).

Outro motivo menos recorrente, mas presente em algumas falas, relaciona a escolha da carreira com a estabilidade trazida por um cargo público e também como forma de ascensão social. Alguns entrevistados relataram ainda certa admiração pelo militarismo, destacando como positivas características como a disciplina e o respeito, que, segundo os entrevistados, são qualidades trazidas pela organização militar. Essa atitude de admiração era ainda confirmada quando os entrevistados eram questionados sobre o significado de ser policial e se escolheriam novamente essa profissão caso pudessem recomeçar. A quase totalidade dos policiais respondeu com convicção que, caso pudesse recomeçar, certamente escolheriam novamente ser policial.

Ainda que as motivações para escolher a profissão passem, em muitos casos, por considerações de ordem prática e econômica, os policiais demonstram valorizar e admirar a profissão por realizar um trabalho importante para a sociedade. Na fala de muitos entrevistados, essa valorização do trabalho passava pela afirmação do que eles entendem ser a função da polícia. A ideia de "combater o crime" aparece com frequência:

Sim. E é muito gratificante assim. Vou falar até de uma maneira chula. Prender um ladrão. É gratificante [...]. Eu acho que é tipo assim que nem quem gosta muito de jogar futebol. Jogador profis- 
sional, qual é o auge dele, é um gol, ou tirar a bola na linha no final do campeonato salvando o time, pra mim é prender um ladrão (Policial 3).

Cada dia que eu passo, cada noite que eu passo na rua eu me apaixono mais, porque se eu conseguir tirar uma pessoa de má índole da rua, é uma pessoa a menos pra fazer o que não presta com minha filha que tá vindo, com meu filho que eu deixei em casa. Então, cada dia que passa... se eu tirar uma pessoa por dia, já valeu a pena. Se eu conseguir prender um bandido por dia, já tá valendo a pena. Mesmo que ele já esteja solto no outro dia, pela audiência de custódia (Policial 13).

Essa concepção do trabalho vinculado ao combate à criminalidade aparece também quando os entrevistados são questionados diretamente sobre o que eles entendem ser a função da polícia. A função era associada à necessidade de controlar a criminalidade, de impedir que crimes ocorram e de reprimi-los quando ocorrem, bem como à manutenção da ordem pública.

\section{O contato com a população}

Conforme destacado por Jonathan-Zamir e Harpaz (2014), a abordagem dialógica da legitimidade envolve não apenas compreender se os detentores do poder acreditam deter o direito moral de exercer autoridade, mas também investigar a percepção que têm da visão da população sobre a polícia e do reconhecimento de sua autoridade. Se, nessa abordagem, a legitimidade é entendida como um processo dinâmico entre reivindicação e reconhecimento da autoridade, é preciso considerar também a percepção dos que exercem o poder sobre o reconhecimento de sua autoridade.

Nas entrevistas com os policiais, buscou-se dar conta dessa dimensão da autolegitimidade a partir de questões sobre o contato e a relação que os policiais estabelecem com a população. A crença de que os policiais detêm o direito de exercer autoridade e a valorização da profissão ocupando posição especial na sociedade, demonstrada nas respostas apresentadas até o momento, contrastam com a visão que os policiais têm da resposta que a população dá ao exercício de sua autoridade. Quando questionados a respeito das dificuldades enfrentadas na realização do trabalho, muitos entrevistados mencionaram "a população" e a falta de respeito que expressam em relação aos policiais. Ao falar sobre essa "falta de respeito", os policiais relatavam inúmeras situações nas quais as pessoas "questionam" as medidas e os procedimentos que adotam. Os exemplos utilizados para ilustrar essa falta de respeito com frequência envolviam as reações negativas das pessoas às abordagens policiais: 
Ah, eu penso que está meio complicado de trabalhar hoje em dia, porque o que eu percebo é que os cidadãos, eles não respeitam mais a polícia assim, sabe? É coisa boba, tá todo mundo muito nervoso, e não respeitam. Tudo quer questionar. Acho que é saudável você questionar, mas tudo tem sua hora, entendeu? As pessoas estão intolerantes. Eles não querem entender que você está trabalhando, não querem entender que tem que ser assim, entendeu? E a gente já sai, a gente já é preparado um ano para entender que existem regras a serem cumpridas. E os cidadãos, eles não estão acostumados a cumprir regras, então tem esse choque, assim. Tem coisa que eu fico indignada, sabe? [...] As pessoas não quererem ouvir. Como fazer a pessoa entender que eu posso, que está na Lei, que existe poder de polícia, que eu tô amparada legalmente. Eu posso te abordar, eu posso te revistar, eu posso! (Policial 8, grifo nosso).

É que nem a pessoa que ela não deve nada, ela nunca teve problema nenhum com a Justiça, nada, vai andar com o carro um dia. Aí você vai abordar ela, ela se acha intocável. Você não tem o direito de abordar ela. Muitos questionam. Aí eu falo que não tem respeito porque tipo assim eu penso, se eu não devo... eu não temo, né? Aí as pessoas se sentem intocáveis. "Eu não quero ser abordado porque eu sou trabalhador". Eu falei, mas em qual momento eu disse que você não é trabalhador. Aí acaba havendo vários conflitos no decorrer do serviço, mas é uma coisa que a gente acostuma. Porque é meio que digamos que de lei. [...] A gente é muito questionado, né? Aí muitas vezes a gente tem que jogar artigo. Ah você pode tá me abordando, aí você tem que jogar o artigo, do poder de polícia, né? Aí a pessoa fica quieta, né? Não sabe nem o que você tá falando, mas fica quieta (Policial 3, grifo nosso).

Infelizmente algumas pessoas não entendem o nosso trabalho, isso dificulta. As pessoas muitas vezes não sabem o que a polícia tá fazendo, porque tá abordando, porque isso e aquilo, né? É que nem como eu disse né, aqui por ser uma área de uma classe um pouco mais alta, as pessoas às vezes não entendem o seu trabalho. Acha né, que tipo pouco, acha que não tem necessidade, porque você tá abordando e tal, né? Mas isso aí a gente conversa com poucas pessoas as vezes, as pessoas que querem ouvir, a gente acaba conversando, explicando e tudo certo, né? (Policial 6).

Como é possível observar nos trechos acima, a dificuldade que os policiais relatam enfrentar no contato com a população envolve a falta de reconhecimento de sua autoridade. Trata-se, portanto, de um problema de legitimidade. É interessante observar que a reclamação a respeito da resposta da população passa pela afirmação da crença no direito que eles detêm de exercer a autoridade, direito esse que estaria amparado na Lei. Com frequência, a explicação oferecida pelos 
entrevistados para esse "questionamento" estava relacionada à falta de conhecimento da população sobre a Lei. Quando o entrevistado fala em "jogar o artigo", de alguma maneira se refere à necessidade de recorrer ao plano normativo para demonstrar a autorização que detém para o exercício do poder na prática. Ao relatar as reações negativas enfrentadas durante as abordagens, os policiais expressam que a população não reconhece o direito e a autorização dos policiais para o exercício de seu poder coercitivo. Independentemente do fato de agirem de modo indevido, abusivo e, no limite, ilegal durante as abordagens, o que é significativo nesses relatos é a percepção dos policiais sobre a falta de reconhecimento de sua legitimidade. As abordagens, enquanto atividade de exercício do poder coercitivo, seriam a realização das atribuições da polícia e o momento, portanto, de exercício de mandato.

A percepção dos policiais sobre as reações negativas às abordagens acompanha o resultado de outras pesquisas. O modelo instrumental de controle social criticado por Tyler é justamente aquele fundado na ameaça da punição como forma de motivar o comportamento. Os estudos do autor partem da constatação de que esse modelo de policiamento tem efeitos negativos para a legitimidade percebida da polícia. Tyler (2011) comenta especificamente que as abordagens - utilizadas crescentemente como estratégia chave para controlar a criminalidade em grandes centros urbanos - apresentam como efeito colateral negativo a diminuição da confiança na instituição policial e da disposição dos cidadãos para a cooperação e a obediência voluntária.

Em pesquisa recente, também realizada com policiais da PMESP, Melina Risso (2018) analisou a visão dos policiais sobre as abordagens e verificou que essas também são adotadas como estratégia central da política de segurança pública do estado de São Paulo: somente no ano de 2016, foram realizadas 14 milhões de abordagens. Na mesma direção do que foi identificado nesta pesquisa, Risso demonstra que os policiais compreendem o "combate ao crime" como função primordial da polícia e valorizam as abordagens como instrumento central da realização dessa função. No que diz respeito à resposta da população, os entrevistados de Risso também reclamam da falta de respeito e de compreensão, bem como das reações negativas e dos questionamentos acerca de sua autoridade. A autora conclui que tais reações negativas às abordagens decorrem do fato de ser um tipo de interação com a população fundada na desconfiança.

O mesmo tipo de disjunção parece acontecer em relação ao que os policiais entendem ser a função de seu trabalho e que justificaria o tipo especial de autoridade. Quando os entrevistados falam sobre sua rotina de trabalho e o tipo de ocorrência 
que geralmente atendem, afirmam que a população não entende qual é o trabalho da polícia e apresenta demandas excessivas que - segundo eles mesmos - seriam um desvio de função. Ao serem questionados sobre sua rotina, os policiais mencionaram que a grande maioria das ocorrências se enquadram no que eles chamam de "desinteligência".

Segundo o estudo de Adilson Nassaro (2012), o termo desinteligência é usado tecnicamente pela PMESP para classificar (código C-04) as ocorrências relativas a "desavenças entre vizinhos por incômodos diversos", lesão corporal leve e dano simples. De forma semelhante e, por vezes concorrentes, existem as ocorrências classificadas como "perturbação do sossego" (código C-01), caracterizada por conflitos envolvendo barulho e som alto, festas não autorizadas em vias públicas, como os chamados "pancadões" ${ }^{2}$. Ainda segundo o autor, a palavra é acionada comumente no meio policial para

identificar uma ocorrência de falta de acordo ou de compreensão, de desentendimento, de divergência ou inimizade entre as partes, porém sem configurar crime (Nassaro, 2012: 41).

Assim, no cotidiano dos policiais, o termo desinteligência é acionado para fazer referência às ocorrências não criminais e que, do ponto de vista deles, não são ou não deveriam ser atribuições da polícia. São ocorrências relacionadas às demandas da população para a solução de conflitos interpessoais e que representam a maior parte dos chamados recebidos.

É briga, marido e mulher brigando, pai e filho, irmão brigando. E som alto. O povo tem reclamado bastante, só que é mais na parte da noite. Durante o dia é mais tranquilo. Agora, à noite tem bastante som alto. [...] Porque, na maioria das vezes, essas brigas aqui na área é cachaça mesmo. É sempre o mesmo motivo. Então a gente tenta resolver ali, porque uma hora depois, duas horas depois passou o efeito já vai tá tudo bem. Um já vai tá pedindo perdão pro outro. Então já vai ter passado o estresse, né? Sempre tentando resolver, aí não deu pra resolver?, é delegacia (Policial 1).

Aqui tem muita perturbação de sossego, que é o som alto e desinteligência. Ainda a desinteligência e a perturbação de sossego é muito alto. Claro que tem os roubos, tem as partes mais criminosas, mas ainda, o problema social ainda é maior, a discussão entre vizinhos, enfim. Desinteligência é muito maior, tem muito desentendimento. Se você for pro Copom (Centro de Operações da Polícia Militar), conversar com o pessoal de lá, falar eu quero uma planilha geral de como, a polícia acho que recebe mais ligações, quais são as porcentagens de cada ocorrência? Desinteligên-

\author{
2. Em determinadas \\ áreas da cidade \\ de São Paulo \\ são organizadas \\ informalmente festas \\ noturnas nas ruas, \\ nas quais a música \\ é tocada em caixas \\ de som ou em carros \\ com equipamentos \\ sonoros de alta \\ potência, reunindo \\ um número elevado \\ de participantes. \\ Estas festas são \\ usualmente \\ chamadas de \\ "pancadões", em \\ referência direta ao \\ estilo e volume da \\ música.
}


cia, perturbação de sossego, roubos, furtos, você vai ter acesso maior lá e você vai ver que $70 \%$ é desinteligência e perturbação do sossego (Policial 16).

Ao descrever as ocorrências atendidas no dia a dia, os policiais relatavam que havia um excesso nas demandas da população, com a expectativa de que a polícia solucionasse os mais diversos tipos de conflitos e situações. Muitos policiais acreditam que boa parte destas demandas não são da alçada da PM e que a população espera a solução de seus conflitos mesmo que a polícia não tenha competência para tanto. Frequentemente os policiais relacionavam esse excesso nas demandas feitas pela população à necessidade de outros serviços públicos, como a assistência social, jurídica etc. O que faz com que o policial também atue na orientação e encaminhamento dos mais diversos tipos de conflitos.

Às vezes a pessoa liga para a PM e às vezes ela só quer conversar. Acaba sendo um pouquinho de tudo [...]. A gente vê quem é a pessoa, porque que ela solicitou a viatura e em cima daquilo a gente vai trabalhando, falando assim: ô, infelizmente isso aí não é pela Polícia Militar, é parte da assistência social, não, né, a gente vai distribuindo para setores, órgãos ou municipal ou estadual para ela estar administrando (Policial 12).

São questões de briga de marido e mulher, por questões do dia a dia, pensão alimentícia, a gente é acionado para resolver questão trabalhista! Aí você pega um martelo de juiz e vai resolver. Eu falo assim sempre para o meu pelotão: nós somos mediadores, pense que você é um mediador. [...] Hoje mesmo teve uma ocorrência assim:

- Sargento, minha patroa não quer me pagar.

- Minha senhora, a senhora tem que procurar a Justiça do Trabalho, eu não posso pegar sua patroa e obrigar ela a assinar um cheque. Isso quem decide é o juiz, depois dele analisar todo um processo, de entender que a senhora tem vínculo, não tem, quanto tempo, fazer cálculo.

Então, às vezes, a pessoa não sabe. Ela acha que acionando o 190 a polícia vai resolver. E às vezes a gente chega e explica que não pode resolver tudo e a pessoa sai chateada porque a polícia não resolveu (Policial 25).

A população espera que a gente supra todas as necessidades. Essa é a realidade [...]. A ocorrência que mais cai, não sei se vocês sabem disso, é desinteligência entre marido e mulher, entre amigos, entre pai e mãe, as pessoas acham que isso é crime, então sempre acionam e isso é a ocorrência que mais cai é a desinteligência [...]. Muitas coisas não cabe a gente fazer. Por exemplo, dentro da sua casa, o que que eu vou falar para você dentro da sua casa. Então a população espera muito da gente, porém eles não fazem muita 
coisa para ter o retorno. A gente vai, orienta, o que dá para fazer, muitas vezes só a presença do policial já baixa os ânimos. O pessoal vai dormir, mas a população espera que a gente supra todas as necessidades. O meu gato está em cima da árvore, chama a polícia, a minha mãe gritou comigo, chama a polícia (Policial 17).

Existe, assim, a visão de que a população aciona e recorre excessivamente à polícia, espera que ela seja capaz de resolver os mais diferentes tipos de problema. Parte importante do trabalho dos policiais envolveria, portanto, ocorrências não criminais e que consistiriam em desvios da função do policial. Na fala dos policiais, também é possível perceber que essa visão de que são ocorrências que não são de responsabilidade deles está associada ao pouco preparo para lidar com esse tipo de situação. A visão dos policiais indica que a formação recebida na escola de soldados não prepara os policiais e tampouco apresenta recursos necessários para que eles possam atender às demandas que a população formula. Como apontado por Paula Poncioni (2007), a formação policial prioriza as atividades relacionadas ao controle e ao enfrentamento das ocorrências criminais e pouco prepara os policiais para interagir com a população e para a mediação de conflitos não criminais.

Conforme indicado, a ideia de que a função do policial é atuar exclusivamente em conflitos criminais é estimulada pelo próprio direcionamento das políticas de segurança pública pautado no enfrentamento e no discurso da "guerra ao crime" - especialmente nos casos relacionados ao tráfico de drogas e ao chamado crime organizado (Silvestre, 2018). A lógica da guerra, preconizando a existência de um inimigo a ser combatido, tem mais aderência na realidade cotidiana dos policiais do que programas orientados por outras doutrinas, como o policiamento comunitário, por exemplo, ainda que existentes em São Paulo. Esse direcionamento das políticas de segurança pública, fundado no modelo instrumental da dissuasão, privilegia as abordagens policiais e as prisões como instrumento central de controle da criminalidade. A situação relatada pelos policiais também reforça os argumentos desenvolvidos por Egon Bittner (2003) de que a definição programática do papel da polícia como organização que combate o crime e aplica a lei não condiz com a maior parte do trabalho diário dos policiais, que envolve todos os tipos de situação que possam exigir o uso da força. Por este motivo, o autor defende que a polícia deve ser definida como um "mecanismo de distribuição, na sociedade, de força justificada pela situação" (Bittner, 2003: 130). A ideia de que a polícia é basicamente uma agência de controle do crime produziria um uso excessivo de prisões como forma de justificar as ações dos policiais e um efeito negativo sobre a moral dos policiais que gastam a maior parte do seu tempo lidando com outro tipo de questão. A falta de avaliação dessas atividades levaria ainda à negligência no desenvolvimento de habilidades e no conhecimento para que sejam executadas de modo apropriado e eficiente. 
3. Essa distinção entre contatos "autoiniciados" e contatos iniciados pela polícia ou pela Justiça é um aspecto considerado na pesquisa do Programa Cepid realizado com a população da cidade de São Paulo. As questões do survey buscam especificar esse aspecto do contato e já foi possível identificar diferenças significativas nas percepções e atitudes das pessoas que procuram a polícia com relação àquelas que são abordadas (NEV, 2018).
O que as visões dos entrevistados sobre os contatos com os cidadãos demonstram é que existe uma disjunção entre a forma como os policiais concebem sua função e enxergam sua autoridade, de uma parte, e as respostas e demandas da população, de outra. Se compreendemos que a legitimidade policial, a partir do ponto de vista do público, consiste no reconhecimento do direito moral do policial exercer poder e ditar comportamento, a demanda que a população expressa quando "chama a polícia" para resolver ou mediar os mais diversos tipos de conflitos poderia ser compreendida pelos policiais como reconhecimento de sua autoridade. No entanto, a ênfase na doutrina da "guerra" e do "combate ao crime" - não apenas na forma como os policiais definem o seu trabalho, mas também na visão sobre o que fundamenta o seu valor na sociedade - faz com que os policiais rejeitem essas demandas da população. Em contrapartida, no tipo de atuação que os policiais compreendem como exercício devido de seu mandato - a realização de abordagens -, os policiais identificam um déficit de legitimidade.

É interessante observar que essa diferença se manifesta entre dois tipos diferentes de contato entre cidadãos e policiais: os contatos iniciados pela população e os contatos iniciados pela própria polícia ${ }^{3}$. O primeiro tipo, de caráter voluntário, é visto pelos policiais como gerando demandas distorcidas e excessivas que os obrigam a realizar atividades que não estão de acordo com sua função. Já os contatos iniciados por eles, de caráter coercitivo, traduziriam corretamente o exercício de seu mandato e, no entanto, envolveriam reações negativas da população que demonstra não reconhecer sua autoridade.

\section{Considerações finais}

A literatura internacional dedicada ao estudo da legitimidade policial tem demonstrado que a confiança que os policiais dispõem em sua autoridade tem efeitos no tipo de policiamento que defendem e realizam nas atividades diárias. A proposta de Tyler (1990; 2003; 2011) - principal inspiração desses estudos - envolve a visão de que a legitimidade dos agentes públicos, e mesmo das instituições do sistema de justiça criminal, é fortemente influenciada pelo tipo de contato e interação que a população tem com os agentes públicos. Quando a autoridade é exercida com procedimentos percebidos pelos cidadãos como justos, igualitários e transparentes, há maior chance de que esses cidadãos reconheçam o direito ao exercício do poder por parte destes agentes. Da mesma forma, é possível pensar que esse contato também é relevante para a constituição da autolegitmidade desses agentes. As possíveis disjunções entre o que constitui a reivindicação dos policiais com relação a sua autoridade e sua função e percepção sobre as respostas da população podem ter efeitos significativos em sua forma de exercer as atividades diárias no contato com o público. 
O que as entrevistas realizadas demonstram é que, ainda que os policiais acreditem dispor do direito de exercer sua autoridade, parece haver uma tensão entre a expectativa de um trabalho baseado no heroísmo, na adrenalina e no "combate" ao crime e a realidade de um trabalho voltado à solução de conflitos interpessoais. Por um lado, a expectativa dos entrevistados com relação à profissão de policial e o que os faz admirar a profissão e atribuir a ela um valor especial na sociedade é a ideia de "combate ao crime". De maneira semelhante, o tipo de atividade que eles entendem como o exercício de seu mandato envolve realizar abordagens, um contato com a população de caráter também coercitivo. Por outro lado, a quase totalidade dos policiais afirma que a maior parte das demandas de trabalho com as quais eles lidam envolve mediação de conflitos entre familiares e vizinhos, sejam brigas ou "som alto". Ao comentarem sobre essas demandas e as ocorrências não criminais, os policiais expressam seu descontentamento com a diversidade e o excesso dos pedidos da população que os obrigaria a atuar em situações que não seriam de sua responsabilidade.

Assim, ao relatar seu cotidiano de trabalho e as dificuldades enfrentadas no trato com a população, os policiais constroem um problema que é fundamentalmente de legitimidade. Quando exercem a atividade coercitiva autorizada por seu mandato, os policiais sentem que sua autoridade é constantemente questionada e desrespeitada. Em contrapartida, as ocorrências resultantes das demandas da população, que poderiam ser percebidas por eles como reconhecimento de sua autoridade, são vistas como desvios em relação a suas atribuições.

Com essa discussão, é possível demonstrar que a manutenção do modelo de atividade policial baseada na noção de "guerra ao crime" e de uma organização militar baseada em regulamentos rígidos de disciplina interna - que ignora o trabalho discricionário e a capacidade de tomar decisões intrínsecas ao trabalho policial - apresenta ainda uma consequência adicional: prejudica a autolegitimidade dos policiais.

\section{Referências}

ADORNO, Sérgio; NERY, Marcelo Batista. Crime e violências em São Paulo: retrospectiva teórico-metodológica, avanços, limites e perspectivas futuras. Cadernos Metrópole, v. 21, n. 44, p. 169-194, Abr. 2019.

BITTNER, Egon. Aspectos do trabalho policial. São Paulo: Editora Universidade de São Paulo, 2003. 
BOTTOMS, Anthony; TANKEBE, Justice. Beyond procedural justice: a dialogic approach to legitimacy in Criminal Justice. The Journal of Criminal Law \& Criminology, v. 102, n. 1, p. 119-170, 2012.

BRADFORD, Ben; QUINTON, Paul. Self-legitimacy, police culture and support for democratic policing in an English Constabulary. British Journal of Criminology, p. 1-24, 2014. Disponível em: <http://doi.org/10.1093/bjc/azu053>.

BUENO, Samira. Letalidade na ação policial. In: LIMA, Renato Sérgio de; RATTON, José Luiz; AZEVEDO, Rodrigo Ghiringhelli (Orgs.). Crime, polícia e Justiça no Brasil. São Paulo: Contexto, 2014

CANO, Ignacio; DUARTE, Thais. Análise comparativa das legislações disciplinares das corporações de segurança pública: uma proposta de matriz de lei disciplinar para o Brasil. Brasília: Senasp; 2012.

CARUSO, Heydée et alii. Da escola de formação à prática profissional: um estudo comparativo sobre a formação de praças e oficiais da PMERJ. Segurança, Justiça e Cidadania, Ano II, n. 4, Brasília, Secretaria Nacional de Segurança Pública do Ministério da Justiça, 2010.

JONATHAN-ZAMIR, Tal; HARPAZ, Amikam. Police understanding of the foundations of their legitimacy in the eyes of the public: the case of commanding officers in the Israel National Police. British Journal of Criminology, v. 54, n. 3, p. 469-489, 2014.

KANT DE LIMA, Roberto. Ensaios de antropologia e de direito: acesso à justiça e processos institucionais de administração de conflitos e produção da verdade jurídica em uma perspectiva comparada. Rio de Janeiro: Lumen Juris, 2011.

A polícia da cidade do Rio de Janeiro: seus dilemas e paradoxos. Rio de Janeiro: Forense, 1995.

LIPSKY, Michael. Street-level bureaucracy: dilemmas of the individual in public services. New York: Russell Sage Foundation, 2010

MISSE, Michel et alii. Letalidade policial e indiferença legal: a apuração judiciário dos "autos de resistência" no Rio de Janeiro. Dilemas: Revista de Estudos do Conflito e Controle Social, Edição especial n. 1, p. 43-71, 2015.

MUNIZ, Jacqueline. Direitos humanos na polícia. In: LIMA, Renato Sérgio de; PAULA, Liana de (Orgs.). Segurança pública e violência: o Estado está cumprindo o seu papel?, p. 65-75. São Paulo: Contexto, 2008. 
. "Ser policial é, sobretudo, uma razão de ser". Cultura e cotidiano da Polícia Militar do Estado do Rio de Janeiro. Tese (Doutorado em Ciência Política) - Instituto Universitário de Pesquisas do Rio de Janeiro. Rio de Janeiro, 1999.

MUNIZ, Jacqueline; SILVA, Washington. Mandato policial na prática: tomando decisões nas ruas de João Pessoa. Cadernos CRH, v. 23, n. 60, p.449-473, 2010.

MYHILL, Andy; BRADFORD, Ben. Overcoming cop culture? Organizational justice and police officers' attitudes toward the public. Policing: an International Journal of Police Strategies \& Management, 2013.

NASSARO, Adilson. O Policial Militar pacificador social: emprego da mediação e da conciliação no policiamento preventivo. Revista LEVS, v. 10 n. 10, Marília, 2012.

NEV. Cepid-Fapesp Program "Building democracy daily: human rights, violence and institutional trust". 5th Report. 2018.

PAIXÃO, Antônio Luiz. Crime, controle social e consolidação da democracia. In: O'DONNELL, Guillermo; REIS, Fábio Wanderley (Orgs.) A democracia no Brasil: dilemas e perspectivas, p. 166-199. São Paulo: Vértice; Editora Revista dos Tribunais, 1988.

A organização policial numa área metropolitana. Dados Revista de Ciências Sociais, v. 25, n. 1, p. 63-85, 1982.

PINHEIRO, Paulo Sérgio. Autoritarismo e transição. Revista USP, n. 9, Mar./Maio 1991.

PONCIONI, Paula. Tendências e desafios na formação profissional do policial no Brasil. Revista Brasileira de Segurança Pública, Ano I, n. 1, 2007.

. O modelo policial profissional e a formação profissional do futuro policial nas academias de polícia do estado do Rio de Janeiro. Sociedade e Estado, v. 20, n. 3, p. 585-610, 2005.

RAZ, Joseph. Between authority and interpretation: on the theory of law and practical reason. Oxford (UK): Oxford University Press, 2009.

RISSO, Melina. Da prevenção à incriminação: os múltiplos sentidos da abordagem policial. Tese (Doutorado em Administração Pública) - Escola de Administração de Empresas de São Paulo, Fundação Getúlio Vargas, São Paulo, 2018.

SILVESTRE, Giane. Controle do crime e seus operadores: política e segurança pública em São Paulo. São Paulo: Annablume, 2018. 
SINHORETTO, Jacqueline et alii. A filtragem racial na seleção policial de suspeitos: segurança pública e relações raciais. In: FIGUEIREDO, Isabel (Org) Segurança pública e direitos humanos: temas transversais, p. 121-159. Brasil: Ministério da Justiça, 2014.

TANKEBE, Justice. Explaining police support for the use of force and vigilante violence in Ghana. Policing \& society, v. 21, n. 2, p. 129-149, 2011.

Public confidence in the police: Testing the effects of public experiences of police corruption in Ghana. The British Journal of Criminology, v. 50, n. 2, p. 296319, 2010.

TEIXEIRA, Paulo A. S. Processos de treinamento no uso da força para policiais militares da Região Sudeste: uma análise preliminar. Revista Brasileira de Segurança Pública, Ano III, edição 4, p. 6-19, Fev./Mar. 2009.

TYLER Tom R. Trust and legitimacy: policing in de USA and Europe. European Journal of Criminology, v. 8, n. 4 , p. 254-266, 2011.

. Procedural justice, legitimacy, and the effective rule of law. Crime and Justice, v. 30, p. 283-357, 2003.

Why people obey the law: procedural justice, legitimacy, and compliance. New Haven (CT): Yale University, 1990.

VARGAS, Joana. Em busca da "verdade real": tortura e confissão no Brasil ontem e hoje. Sociologia \& Antropologia, v. 2, n. 3, p. 237-265, 2012. 